\title{
Labial Adhesion in Adult Female
}

\section{${ }^{1}$ Seetesh Ghose, ${ }^{2}$ P Pallavee, ${ }^{3}$ Jasmina Begum, ${ }^{4}$ Lopamudra B John, ${ }^{5}$ Sunil Kumar Samal}

\begin{abstract}
A 23 years old female presented to gynecological outpatient department (OPD) with complain of passing urine and menstrual blood through a single small opening for 5 years. On examination, she had well developed secondary sex characters but fused labia minora with a single pinpoint opening through which she was passing both urine and menstrual blood. Radiological investigation revealed normal female genital tract. So, the case was diagnosed as labial fusion and surgically treated as medical management failed.
\end{abstract}

Keywords: Adhesion, Estrogen, Labia, Surgery, Woman.

How to cite this article: Ghose S, Pallavee P, Begum J, John LB, Samal SK. Labial Adhesion in Adult Female. J South Asian Feder Obst Gynae 2015;7(3):207-209.

Source of support: Nil

Conflict of interest: None

Date of received: 9 August 2015

Date of acceptance: 11 October 2015

Date of publication: December 2015

\section{INTRODUCTION}

Labial adhesion is a benign genital disorder seen in girls or in postmenopausal women, but are extremely rare in reproductive women. It may be either congenital or acquired. ${ }^{1,2}$ Although its incidence has been reported as approximately 0.6 to $3.0 \%$, rates as high as 21.3 and $38.9 \%$ have been documented with a peak incidence of 13 to 23 months of age. ${ }^{3,4}$ However, labial adhesion have been reported in women who are postpartum, postmenopausal and those with coexisting vulvar lesion. ${ }^{5}$ We are reporting a case of labial adhesion in female of reproductive age group, whose incidence is not known, as it goes unreported.

\section{CASE REPORT}

Miss X, 23 years old, unmarried referred to gynecology Outpatient Department (OPD) as vaginal atresia. Her

\footnotetext{
${ }^{1}$ Professor, ${ }^{2-4}$ Associate Professor, ${ }^{5}$ Assistant Professor

${ }^{1-6}$ Department of Obstetrics and Gynecology, Mahatma Gandhi Medical College and Research Institute, Puducherry, India
}

Corresponding Author: Seetesh Ghose, Professor Department of Obstetrics and Gynecology, Mahatma Gandhi Medical College and Research Institute, Puducherry, India Phone: 9443244630, e-mail: seetesh@mgmcri.ac.in history is as follows: She was alright 5 years back, when she noticed narrowing of the introitus and visited a gynecologist. She was advised to undergo dilation at that time, which she differed till her marriage got fixed. She complained of passing urine and menstrual blood through a single small opening since last 5 years. She is the only child of her parents and was born without any genital tract abnormality. She attended menarche at 13 years of age. It was regular, normal in amount and duration with occasional dysmenorrhea. Her bladder and bowel habit was normal. There was no history suggestive of any local perineal trauma, infection or use of any substance locally. There was no history suggestive of any major medical, surgical or dermatological disorder. On examination, her body mass index (BMI) was 21.1. Her secondary sex characters are well developed and vitals are stable. Local examination revealed normal labia majora, fused labia minora with leukoplakia all around it and a small pinpoint opening (Fig. 1).

Preliminary transabdominal ultrasound revealed normal size uterus, ovaries and kidneys without any collection in the pouch of Douglas or abdomen. These findings were confirmed subsequently with magnetic resonance imaging (MRI) (Fig. 2).

Diagnosis of labial fusion was made. Plastic surgeon and urologist were consulted and planned for local application of estrogen cream for 6 weeks and surgical correction after that if required. On review after 6 weeks, there was no improvement in the condition, so surgical correction was planned. Vaginoscopy prior to surgical correction revealed normal cervix and urethral opening behind the fused labia minora (Fig. 3). Fused labia minora was incised, biopsy from the cut margin was taken and the cut margin was stitched interruptedly with 1-0 catgut (Fig. 4). Histopathology of the local tissue revealed evidence of fibrosis. She was advised to continue local application of estrogen for 2 weeks postoperatively. Follow-up after 8 weeks revealed normal external genital. She is advised to undergo regular follow-up at 3 months interval at least for 1 year.

\section{DISCUSSION}

The external female genitals consists of the labia majora and the labia minora. The two labia minora lie on either side of the vagina and urethra, only to intersect at the clitoris. In 'labial adhesions', the labia minora get adhered to each other. It is usually noticed by a parent 


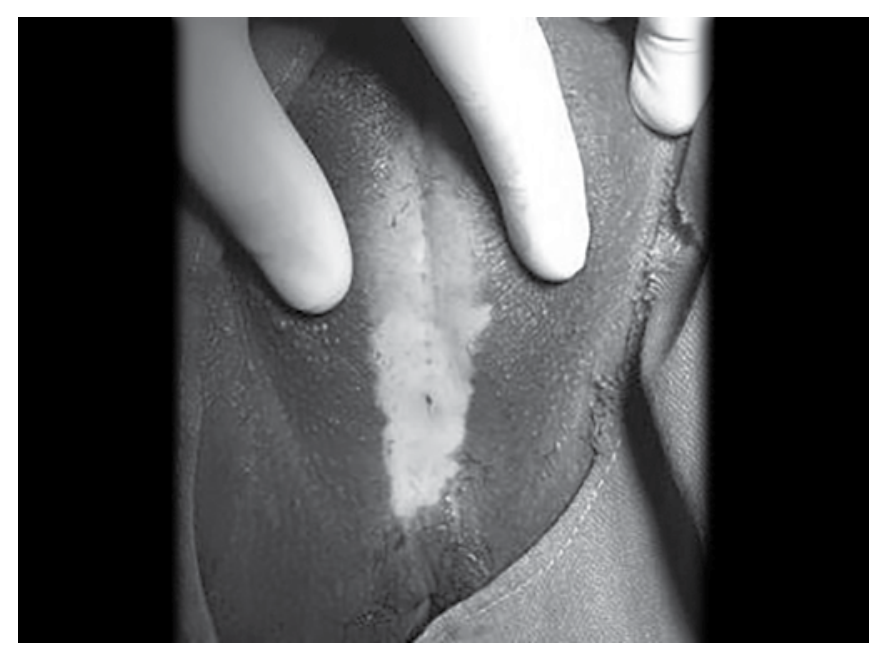

Fig. 1: Fused labia minora with leukoplakia all around it and a small pinpoint opening
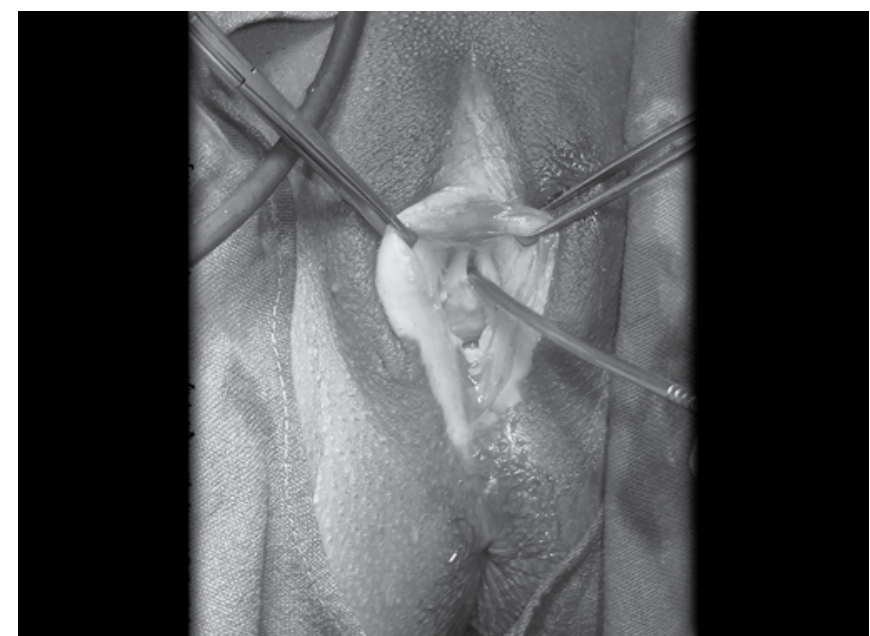

Fig. 3: Normal cervix and urethral opening behind the fused labia minora

or other carer of a girl in the toddler age group as a fleshy membrane joining the labia minora of the vulva, completely concealing the vaginal opening and leaving only a very small opening at the front through which she passes urine. It gives an impression of absent vagina. The condition is usually painless. Sometime there may be vulval soreness after urinating, dribbling urine after going to the toilet may be a problem. In severe cases, there may be an inability to pass urine. Some of the possible complications of labial adhesions include change of the direction of the urine stream, urinary tract infections and hydronephrosis. The exact cause is unknown, but it is suspected that labial adhesions are caused by irritation to the external genitals. The range of possible irritants includes: feces, urine, strongly perfumed soaps, bubble baths, poor hygiene leading to inflammatory conditions, such as vulvitis, atopic dermatitis, pinworms, cicatrisation following trauma, delivery or sexual abuse delivery or condition leading to hypoestrogenic condition. ${ }^{6}$ The outer skin surface (squamous epithelial layer) of the labia

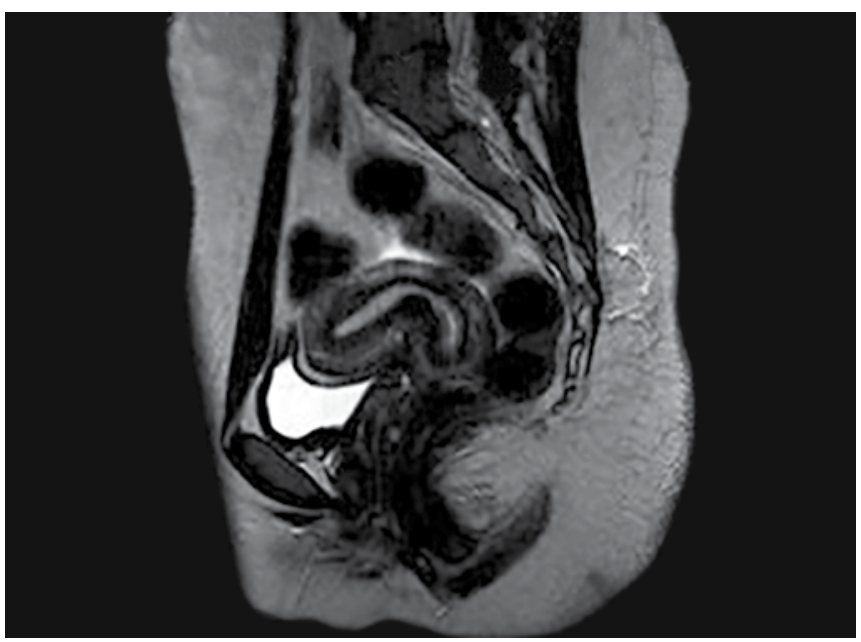

Fig. 2: Normal size uterus, ovaries and kidneys without any collection in the pouch of Douglas or abdomen

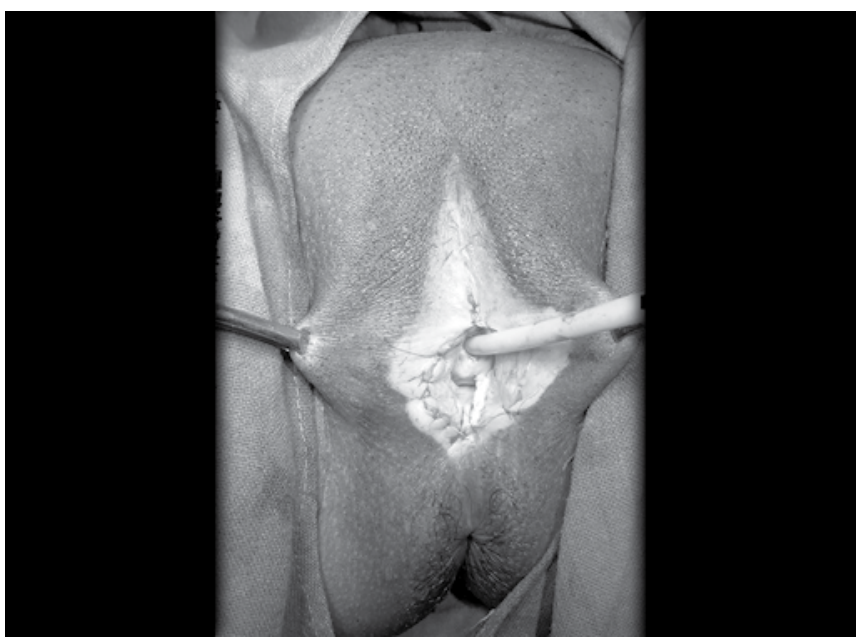

Fig. 4: Interrupted sutures of incised labial margin

minora is thin and delicate. Due to irritation and inflammation, it becomes raw. In the process of healing, the labia start to fuse at the bottom end (posterior fourchette), closest to the anus, and workup toward the clitoris. Poor hygiene is thought to be a common cause in older girls. Some authors have suggested that in some cases labial adhesion could be an early stage of lichen sclerosis. ${ }^{7}$ Labial adhesion resolves spontaneously at puberty in up to $80 \%$ of girls. Most treatment recommends application of estrogen cream 1 to 2 times a day for 4 to 6 weeks. ${ }^{8}$ The success rate of such creams is reported in the literature to be close to $90 \%$ with mild and transient side effect. Surgical adhesiolysis under anesthesia is required in 5 to $10 \%{ }^{9}$ It has a $40 \%$ recurrence rate after treatment, whether medical or surgical. ${ }^{3}$ It is imperative to treat with local estrogen after surgical or manual lysis to prevent recurrence. The uniqueness of our case is asymptomatic, late onset, without any identifiable cause. Our patient need long-term follow-up to see whether she is developing dermatological condition like lichen sclerosis or not. 


\section{ACKNOWLEDGMENT}

We acknowledge the Department of Radiology to arrive at the preoperative diagnosis and Department of Plastic Surgery for their valuable opinion regarding postoperative management.

\section{REFERENCES}

1. Gaudens DA, Moh-Ello N, Fiogbe M, Bandre E, Ossoh BM, Yaokreh JB, et al. Labial fusion in the paediatric surgery department of Yopougon University hospital (Côted'Ivoire): 108 cases. Sante 2008;18(1):35-38.

2. Tsujita Y, Asakuma J, Kanbara T, Yoshii T, Azuma R, Sumitomo M, et al. A case of labial adhesion in a reproductive woman. Hinyokika Kiyo 2010;56(8):463-465.
3. Al Jurayyan NAM. Labial agglutination (Adhesion) in prepubertal girls. What a primary care physician should know? Primary Health Care 2012;2(5):128.

4. Leung AK, Robson WL, Tay-Uyboco J. The incidence of labial fusion in children. J Paediatr Child Health 1993;29:235-236.

5. Herieka E, Dhar J. Labial adhesions following severe primary genital herpes. Sex Transm Infect 2001;77(1):75.

6. Saied SMA. Synlabia after severe monilia infections: a case report. Infect Dis Obstet Gynecol 2011;2010.

7. McCann J, Wells R, Simon M, Voris J. Genital findings in prepubertal girls selected for nonabuse: a descriptive study. Pediatr 1990;86(3):428-439.

8. Goldman RD. Child health update: estrogen cream for labial adhesion in girls. Can Fam Physician 2013;59(1):37-38.

9. Muran D. Treatment of prepubertal girl with labial adhesion. J Pediatr Adolesc Gynaecol 1999;12(2):67-70. 